\title{
Fénelon. Mystique et Politique (1699-1999), Actes du colloque international de Strasbourg, publiés par F.-X. CUCHE et J. LE BRUN
}

\section{Benedetta Papasogli}

\section{(2) OpenEdition}

1 Journals

\section{Edizione digitale}

URL: http://journals.openedition.org/studifrancesi/33141

DOI: 10.4000/studifrancesi.33141

ISSN: 2421-5856

\section{Editore}

Rosenberg \& Sellier

\section{Edizione cartacea}

Data di pubblicazione: 1 décembre 2005

Paginazione: 636-637

ISSN: 0039-2944

\section{Notizia bibliografica digitale}

Benedetta Papasogli, «Fénelon. Mystique et Politique (1699-1999), Actes du colloque international de Strasbourg, publiés par F.-X. cuche et J. LE BRUN», Studi Francesi [Online], 147 (XLX | III) | 2005, online dal 01 novembre 2015, consultato il 18 avril 2021. URL: http://journals.openedition.org/studifrancesi/ 33141 ; DOI: https://doi.org/10.4000/studifrancesi.33141

Questo documento è stato generato automaticamente il 18 avril 2021.

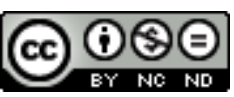

Studi Francesi è distribuita con Licenza Creative Commons Attribuzione - Non commerciale - Non opere derivate 4.0 Internazionale. 


\title{
Fénelon. Mystique et Politique (1699-1999), Actes du colloque international de Strasbourg, publiés par F.-X. CUCHE et J. LE BRUN
}

\author{
Benedetta Papasogli
}

\section{NOTIZIA}

Fénelon. Mystique et Politique (1699-1999), Actes du colloque international de Strasbourg, publiés par F.-X. CUCHE et J. LE BRUN, Paris, Honoré Champion, 2004, pp. 587.

1 Il 1999 fu per più ragioni un anno feneloniano: era il tricentenario della condanna delle Maximes des Saints e, insieme, della pubblicazione del Télémaque, non casualmente contemporanea al momento di sfortuna del vescovo di Cambrai. Fra le iniziative che sottolinearono, in Francia e in Europa, la duplice ricorrenza, la più rilevante e complessa fu certamente il convegno di cui ad anni di distanza sono apparsi gli atti nel volume che presentiamo. L'accostamento fra i due libri più celebri di Fénelon ha permesso ai quasi quaranta specialisti intervenuti al convegno di compiere nell'orizzonte feneloniano un giro a tutto campo, di cui nemmeno il binomio del titolo, pur così suggestivo e aforistico, rende pienamente conto. Mystique et politique può sembrare, non foss'altro nell'eco di parole di Péguy, la posizione di un'antitesi e l'annuncio di una dialettica ardua: in realtà, è parte del segreto di Fénelon la riconciliazione dei due termini, attraverso una moltiplicazione di soglie e di piani, un gioco di allusioni e di trasparenze che gli esegeti non avranno mai finito di approfondire. Occorre piuttosto interrogare la tripartizione interna al volume, per rendersi conto della complessità dei "enjeux" del convegno e della loro articolazione. Una prima parte, intitolata Le procès des Maximes des Saints et la spiritualité de Fénelon, non tocca soltanto punti relativi alla controversia ma trabocca anche in una rilettura del 
mondo spirituale del Télémaque; la seconda Télémaque: poétique, thématique et signification, esplora a fondo i nessi tra quella spiritualità e la dimensione letteraria del testo feneloniano; una terza parte, Contexte et postérité, si apre in varie direzioni, dai precedenti, ai condizionamenti storici, agli effetti, alla fortuna dell'opera di Fénelon. Fra una introduzione di F.-X.Cuche e di Jacques Le Brun e delle conclusioni di Bruno Neveu, l'imponente dispiegamento dei contributi rappresenta al meglio l'apertura di compasso degli studi feneloniani e la vigorosa salute di cui godono.

2 Per un paradosso forse non casuale, sono gli estremi del compasso a rimanere più esterni agli ambiti di ricerca rappresentati. Nella parte sulle Maximes des Saints non compare uno studio teologico, diciamo di natura tecnica, sulla questione del puro amore; nella parte dedicata al Télémaque, il pensiero politico di Fénelon è meno in causa che non i modi di trasmetterlo e significarlo. Nel vasto "entre-deux" fra teologia mistica e dottrina politica vi è posto per una gradazione disciplinare estremamente varia: dall'approccio storico, e già teologico, dedicato a risuscitare protagonisti o comparse nello scenario della condanna - Massoulié, messo in nuova luce da FrançoisXavier Cuche, e Tronson (richiamato da Ironée Noye), i protestanti Jurieu e Poiret (M. Chevallier), e, in ombra, l'interlocutore impossibile, Nicole (B. Guyon) - a quello filosofico e dottrinale in cui emergono nodi, temi, problemi: il rapporto fra amore e conoscenza (Gabriele Perrotti); la questione della mistica come linguaggio (Anne Ferrari); il richiamo alla tradizione nella controversia semiquietista (Jean-Louis Quentin); il problema sempre aperto, evasivo, della cristologia feneloniana (JeanneLydie Goré); l'idea di Provvidenza e il lessico sostitutivo in cui si incarna nella favola pagana (Gérard Ferreyrolles)... È lo studio di Jacques Le Brun a realizzare la transizione fra le Maximes des Saints e il Télémaque, aderendo "au jour le jour" al periodo più delicato nell'esistenza di Fénelon. E come si entra nell'orizzonte del Télémaque, spiritualità e poetica si declinano in alleanze molteplici: prevale la questione "generica" e retorica, nei contributi di Giorgetto Giorgi e François Trémolières; finissimo e produttivo si rivela l'approccio all'immaginario, nei saggi di Y. Louskoutoff e di Françoise Berlan; il rapporto fra linguaggio letterario e linguaggio figurativo è trattato da E. Lavezzi e da Volker Kapp, toccando anche la storia dell'illustrazione del Télémaque; viene impostata, di fronte alla favola dal trasparente messaggio morale, la questione della significazione simbolica nel saggio di Christine Noille-Clauzade che dalla definizione del mito platonico deriva la ricerca di modelli ermeneutici per la lettura del testo di Fénelon. $\mathrm{E}$ motivi più puntuali, come la rappresentazione del cattivo consigliere (Ronzeaud), la valutazione della corporeità (A. Blanc), i fantasmi dell'aldilà feneloniano (Henk Hillenaar), e ancora e sempre l'enigma della presenza e dell'assenza di un Ulisse completamente reinventato rispetto alla mitografia tradizionale (Mayer), sono l'occasione di tessere le fila dell'ordito che fa del Télémaque un libro unico, e di ritrovare in ogni dettaglio lo specchio di una totalità aperta e insondabile.

3 Prevale nella parte centrale del volume l'interesse per il Télémaque come opera letteraria. Ma fin dall'inizio, non c'era niente di scontato nella "invenzione" critica del racconto pedagogico come capolavoro letterario, epico o romanzesco (lo mostra Emmanuel Bury rievocando la linea della ricezione settecentesca del libro); e il superamento di ogni barriera tra i generi ha l'estrema riprova nella fortuna di Télémaque a teatro e nell'opera lirica, meglio ancora, nella intima affinità del testo di Fénelon con gl'incantesimi scenici e musicali, secondo le indicazioni di J.-Ph. Grosperrin e di L. Nadeix). Anche le pagine finali sulla fortuna di Fénelon nel XIX secolo 
(Gesse) riguardano soprattutto il Télémaque, così che l'intero volume vira decisamente dalla problematica del processo - oggetto di una revisione ormai secolare - a quella dell'effusione e diffusione dello spirito feneloniano nell'immaginario e nella cultura europea. E l'intero corpo degli atti qui raccolti colma brillantemente la lacuna presente nel titolo, dove, tra mistica e politica, nello spazio dell'infinita mediazione e transizione, un terzo termine manca: letteratura. 